\title{
Introduction to the Journal of Bodies, Sexualities, and Masculinities
}

\author{
Jonathan A. Allan, Chris Haywood, and Frank G. Karioris
}

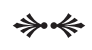

Men's prostate orgasms, cuckold culture, breastfeeding fathers, and erectile dysfunction technologies have epithetically signaled how men's bodies, sexualities, and masculinities have exceeded the gender and sexual order of modernity. A proliferation of practices, discourses, and affects that appear to denaturalize and decenter Western epistemologies of the erotic have generated a number of sociocultural uncertainties around how we understand men and their bodies. Gender and sexual identities that have been veridically located within and on the body are becoming increasingly dispersed. Jeffrey Weeks (2007) suggests that the unifying ideologies about sexuality and gender, promulgated through traditional authorities of the church, the family, and conventional morality, have acted to stabilize the norms and values in place. He suggests that the ideological hold of such authorities has become broken "by decades of challenge and change and eroded by the dissolving powers of global flows, economic modernization, and cultural transformations, as well as by the will for change represented by the everyday choices of countless millions" (2007: 109). The impact of such shifts has been realized in the form of broader social and cultural realization and public reflexiveness about the ontological myths that have pervaded men's identities and practices. In short, the mimetic connection between men's bodies, identities, and practices has been fractured, resulting in increasing awareness of the heterogeneity of what it means to be a man. One of the impacts of this development has been attempts to nostalgically re-establish the old ontological certainties about men and reconstruct a truth of gender and sexuality. It is at this moment, in the slipstream of increasing media scrutiny, political concern, and broader social and cultural interrogation about what it means to be a man, that this journal locates itself. 
Given the increasing uncertainties that surround men and masculinity, it is an exciting time to be introducing the launch of the new Journal of Bodies, Sexualities, and Masculinities. A combination of the increasing visibility of alt-right men's groups, dick pics, ongoing revelations over the Roman Catholic Church and sexual abuse, Incels, online violence, revenge porn, the emergence of the \#MeToo movement, and school shootings have once again made men's issues an important area for popular discussion. When it comes to men, their bodies, and their sexualities, sweeping generalizations often premised on pop psychology come into play with self-explanatory terms such as "masculinities in crisis," "locker-room talk," and "toxic masculinity." More specifically, there appears to be a shift in popular commentaries that elide masculinity and dominance, aggressiveness, and predatorial sexualities. Importantly, for some men this is exactly what masculinity is about: a lived-out gendering that, while temporarily establishing a sense of well-being, becomes destructive and harmful to others. At the same time, for some men such destruction and harm are also experienced by themselves, where pressures and unreal expectations about what it means to be a man may be introjected and then internalized. This has led to much concern about needing to understand how men feel and about gaining an understanding of what they are doing. However, it is also important to recognize that such concerns are part of a broader contemporary cultural agenda: to speak to and about men, masculinities, and sexualities is also to establish and prioritize what can be designated as legitimate discourse. We are at a moment where we need to step back and reflect on how current narratives about men, sexualities, and masculinities are configured both historically and contemporaneously. This involves questioning and challenging the theoretical, methodological, and analytical tools that have traditionally been available to the academy. If men's identities and practices are being refashioned in new and alternative ways, then there is a question about the adequacy of different approaches to generating knowledge and understanding about men in changing times. As a result, a journal should take responsibility not only for what it looks at in terms of men's identities and practices, but it should also be accountable for how it looks at men's identities and practices. 


\section{Looking at Bodies, Sexualities, and Masculinities}

It is at this point, in order to reflect on how, as a journal, we look at masculinity, that we need to shift the register of the discussion. Any editorial remarks in the first issue of a new journal are bound to read something like a manifesto, as they set out not simply the tone of the scholarly content to come, but they also put forward some of the crucial elements and priorities that the journal is founded on and that the editors wish to address. As with many good and not so good ideas, the history of the journal began in a conversation during a conference break at a hotel in Ann Arbor, Michigan. However, the origins of the journal run much deeper, as our discussion gave us an opportunity not only to reflect on and explore current approaches to the studies of men and masculinity, it also enabled the three of us to share our feelings about how questions about men, sexualities, and masculinities were seemingly unanswered across the various forums that we were involved in. Journal introductions and editorials are often, in various degrees of politeness, ways of stating something that is missing from a field. A starting point in our hotel discussion was that we were surprised by the lack of research about what men actually do and feel when men have sex. It was not that men were not being looked at, of course. After all, we were at a masculinity conference. Rather, it was just that discussions about men, masculinities, and sexuality happen in particular ways, such as seeing men as a problem for society or viewing men as having individual problems. We started to consider why it is that men are looked at in particular ways. Nancy Tuana (2004: 197) reminds us that ignorance "should not be theorized as a simple omission or gap but is, in many cases, an active production.” More specifically, Tuana points out that ignorance is more than just a lack; it is embedded within a politics of power. Therefore, to suggest that we need to see more conference presentations, more articles, and more research funding focusing on the absences in the field in some ways simply fills the gap and addresses the symptoms of a broader issue. Furthermore, it is one thing to reflect on the current state of the field from the comfort of a mid-range hotel and a selection of weird (but sometimes wonderful) US drinks; it is another thing to do something about it, especially as we were aware of the broader institutionalization of men and masculinities as an academic field.

We recounted the numerous ways in which the study of men and masculinities has been and continues to be shaped and driven by institutionally inflected disagreements and tensions and how these manifest themselves in practices such as conference calls for papers, the scope and remit of 
journals, employment selection and the recruitment of candidates for university positions, legitimate scholarship, and research funding applications. All academic fields are places where a politics of inclusion and exclusion is lived out and practiced. As Peter Walsh and David Lehmann (2019: n.p.) suggest: "Academics live a life as perpetrators and victims in examination and evaluation rituals enshrined in generations of practice. Unsurprisingly, then, academia has competition at its heart, and the inventiveness of its regulators and administrators in designing ways of evaluating and ranking taps into this core feature of the culture." The best papers do not get published, the most significant research proposal does not receive funding, and the best candidate may not get the job. What is designated as important and significant knowledge and understanding do not receive special status in an academy that often promotes a metrics-led competitive individualism. Furthermore, we are aware that, across the academy, being a woman, being black, and being from working-class heritage is likely to result in lower academic status: it is more difficult to obtain recognition and it involves a continual struggle for legitimacy. A lack of professional recognition is not simply about weak academic work, it is about how academic practices are suffused with a privilege that demarcates who is included and who is excluded. With this in mind, one of the aims of this journal is to ensure that it is the idea or argument that is paramount, not the person submitting the idea or argument. To help in this task, we have assembled a diverse editorial board whose members will review articles and whose politics is underpinned by a commitment to equality and fairness. We also have invited academics across the world to provide reviews of our articles with their expert knowledge of the field, which is a key selection practice.

Another area that we felt was a concern was in the ways that existing opportunities to publish tend to be underpinned by a particular disciplinary focus. Much of the work on masculinity has tended to be indebted to sociology, gender studies, psychology, and cultural studies. We state that there is no single theoretical lens or perspective that has ownership over the "true" understanding of reality, and that to truly come to grips with our world as it is we must recognize a plurality of theoretical insights and perspectives, including, but most certainly not limited to, psychoanalysis, queer theory, Marxism, and whatever exciting developments we see over the years to come. This consideration, in turn, has shaped how we view, how we see men, masculinity, and sexuality; it is important therefore to ensure that the journal is genuinely committed to exploring masculinities, sexualities, and bodies through a broader range of disciplines, theories, and 
methods. Not only do we wish to publish articles from those disciplines that we are personally familiar with, but we also wish to recognize other ways of thinking and understanding that may include literary studies, art, history, sculpture, film, philosophy, and even disciplines beyond the social sciences and humanities such as medicine, biology, nursing, and education. One of the reasons for this is that the journal is committed to exploring and developing new ways of knowing and understanding that give space and visibility to new ways of thinking about bodies, sexualities, and masculinities. More appropriately, it is possible that journals that highlight masculinities, bodies, and sexualities tend to be focused on traditional disciplines and thus by default limit the exposure of new ideas and understandings through other disciplinary approaches. In effect, disciplinary exclusiveness not only closes down different ways of talking about phenomena, it also closes down the possibilities for new ideas.

The limiting of ideas is not simply administered through a narrowing of disciplinary focus, it is also about understanding that the theoretical and conceptual frames that we use may be inherently privileged. As we move forward together, we look forward to growing the field of scholarship on men and masculinities. We want to see scholarship move away from the seemingly persistent whiteness of the field, while also setting out to engage critically with questions of whiteness (Leek and Gerke 2017). Similarly, we wish to be part of decentering the Western world and its particular iterations of masculinities, opening up further discussion and dialogue about what masculinities look like in the "formerly" colonized countries, and, as part of this effort, recognizing the need to, without falling into apoliticality, decolonize our scholarship and thinking and recognize the importance of indigenous scholarship (Innes and Anderson 2015; McKegney 2014; Tengan 2008). We need to ask questions such as: what would it look like to step outside of the box of masculinities as we currently theorize it, and what would it mean to think more persistently about bodies/bodied individuals?

Concepts developed in Northern metropoles have tended to influence knowledge production in the Global South. The conceptual move here is to suggest that knowledge about this area is not simply gained through the operation of methodological rules and regulations, but that these very rules and regulations constitute the possibilities of what can be known. As Carsten Levisen (2017: 383) points out in the context of linguistics, "if we impose categories on a creole or any other postcolonial dialect or language, because this category is relevant in European semantics, then, at best we close our eyes to semantic diversity, but at worst we also exercise conceptual 
colonialism on other speakers' semantics." The journal aims to develop and explore the possibilities of understanding bodies, sexualities, and masculinities in ways that problematize or even exceed contemporary ways of understanding. In other words, current academic tools often have their heritage in Eurocentric discursive regimes that in themselves position and center key concepts and may exclude other ways of thinking. The journal is therefore committed to recognizing a geospatial politics of understanding and in the process is hoping to work through the articles that are attempting to develop the possibilities of decolonizing knowledge. At present, it is important to critically investigate the usefulness of existing models of masculinity and recognize the cultural specificity and how such specificity is configured across vectors of social power such as generation, class, disability, and ethnicity within the diversity of cultural contexts.

\section{Journal Practices as Ethical Caring}

We are stating — clearly and unequivocally — that any study of men, sexualities, and masculinities must acknowledge the importance of feministinformed values and recognize that gender and sexuality are relational and always exist in relation to other nexuses of social power. Therefore, to study masculinities or men is to, at the same time, not forgo thought to the broader gendered picture and structures at play. That picture and those structures at play are not simply out there in a world that requires methodical investigation, they are embedded in our everyday practices and lie at the heart of academic production. Knap van Bogaert and Gboyega Ogunbanjo (2009) remind us that care is a core feminist value. With this in mind, we work with the principle that good research is caring research. This means that in the process of assembling journal editions, we explore the ethical principles that underpin the articles that we receive. In relation to empirical work, we may pay particular attention to how the research was conducted, asking questions about the protocols of informed consent and participant anonymity. For work that is informed more by arts and humanities, where the creative practice is a process of research, it is important to reflect on the principles and aims of the work. Underpinning the ethical approach of the journal and its emphasis on an ethics of care is the importance of focusing on the relationships that the journal develops (Tiidenberg 2020). While much research adheres to standards of professional ethics, this formulaic and context-bound exercise suggests that research ethics stop at the moment 
the methodological section of a journal article has been written. As editors, we believe that the responsibility of caring research should continue and be embedded in the production process of the journal. One of the key practices of a journal is to solicit and carefully manage the reviews of the articles that are submitted.

Jonathan, Chris, and Frank have all experienced rejection from journal boards. Sometimes, the journal has not been the right "fit" or the article being submitted did not resonate with the principles or politics of the journal. At other times, we have noted the implicit methodological priorities within journals and only realized, once articles were being submitted, what they actually were. Whatever the reason, having an article rejected from a journal, for those unlucky enough to have experienced it, is soul-destroying. Often, the quality of that rejection can be found in the accompanying peer reviews, and we have felt that it is really important that we try in some way to address this issue. It is interesting that journal article reviews, sometimes questions to paper presentations at conferences and very often book reviews, often carry the traces of an unpleasant masculine style. There is sometimes a feeling of dismissiveness, in that the ideas being presented do not match the ideas of the reviewer, which is, in turn, supplemented with a list of references that refer either to the reviewer or to someone who works closely with them. Whether or not it is a defence mechanism, we are aware of the amount of self-promotion and/or self-importance embedded in the review. We have also come across reviews that seek to engage in lengthy debates with an article. While this is sometimes viewed as an indication that the article meant something to the reviewer, it is sometimes indicative of an opinion on the part of the reviewer about how the article should have been written. In fact, the commentary is more about the article that the reviewer would like to have written. We have also come across reviews that are one- or two-liners, and, while not being offensive, somehow make you feel short-changed. After such textual encounters, we genuinely wish to provide an experience of the review process that is similar to having a critical friend. Not only does the editorial team review and anticipate any difficulties that an article might have before it is sent out for review, but we also try to ensure that our reviewers are briefed on the kinds of reviews that would be helpful. We are also aware of the difficulties experienced when reviewers disagree with one another. We believe that it is the role of the editors to take a more active role in mediating between the reviews and the directions to the author(s). We will try where possible to avoid sending articles to third reviewers. We are well aware that a third reviewer may ask for revisions that neither of the 
other two reviewers have asked for. It is a frustrating and difficult process and one that begins to verge on the unethical. Importantly, the process and practice of reviewing do not exist in a sociocultural void; rather it can be one way of demonstrating our commitment to an ethics of care.

The emphasis on ensuring our trust of and support and compassion for those whom we work with as journal editors means that we welcome submissions from both early career researchers and more established academics. In both cases, it is important to encourage risk-taking, to encourage the submission of research that challenges and problematizes existing knowledge and understandings. In the case of early career researchers, the pressure of publishing is extremely intense as tenured positions appear to be increasingly scarce and competition is fierce. Sometimes, it can be easier to get published than to propose a new approach to looking at something. In a similar way, but with a different emphasis, we have witnessed many more established academics appear as "powerhouses" of publication, celebrating their umpteenth article. In such cases, the ideas being suggested tend to blur and become indistinct. In such cases, the thrill of writing seems to be confined to the search for the next publication. We would urge more established researchers to submit work to the journal that is risky, problematic, and challenging, providing them with the space to develop their intellectual project. This may not be simply about the subject of the research; it may also involve undertaking new ways of doing research. We have inherited a range of methodological possibilities that remain grounded and informed by more traditional philosophical standpoints. Even with the emergence of research approaches informed by flat ontologies, methods of research tend not to match the innovativeness of the philosophical or theoretical approach. In response, the journal welcomes innovative methodological approaches both in the form of creative practice and in the form of empirically grounded work.

\section{Toward the Future}

Going back to our hotel room discussion, although what men do sexually was not the only theme being looked at, it highlighted an important point. Although the study of men, masculinity, and sexuality has proliferated over the past 20 to 30 years, we felt that much commentary had been focused on understanding men through a concept of masculinity that has in itself become explanatory. Earlier feminist work on masculinity recognized the 
importance of context in the production and shaping of gender relations. Work in the early 1990s by Bronwyn Davies (1993) viewed male and female as concepts that were sustained by teachers as opposite and antithetical but that were constituted by schools as properties of the person. For Davies, the very notion of being a person was a contextually driven production of schooling relations. However, despite the intervention of feminist scholars and those working in the field of masculinity studies, some current approaches to schooling and boys are mirroring a broader cultural moment that endorses an understanding of gender, and specifically masculinity, as a measurable quality. Such work drew upon the need to prioritize context and focus on understanding how gender relations were practiced from the point of view of boys themselves. Thus, work by AnnMarie Wolpe, Jacqui Halson, and Jane Kenway did not simply document what boys did; it attempted to understand why they did it. For example, Jacqui Halson (1989), through her research with girls and boys in secondary schools, argued that there was a significant connection between sexual harassment and masculinity. More specifically, she undertook ethnographic work in schools to piece together how male teachers' and boys' identities became constitutive of girls' experiences of schooling. It was this emphasis on exploring masculinity and its link to the context of sexual politics that prioritized 'boy' as a gendered and sexualized identity that could only be understood in the context of the teacher-pupil relationship, the curriculum, and institutional authority. In short, the study of boys and masculinity gave precedence to the relationships to others in the context, rather than the attribution of an interiority of masculinity. The questions that we asked among ourselves covered how the current field of masculinity studies often fuses the descriptive, the explanatory, and the political (Yar 2012).

Our frustration was not simply about the lack of work in the area, but also about how an institutionally sponsored field of study produces the limits of what we are able to know. For example, we need to be increasingly reflexive about how key concepts in the field of masculinity studies, such as heteronormativity, homosociality, hegemony, and misogyny, shape knowledge and understanding of the phenomena being explored. Furthermore, we were aware of how "masculinity" itself has become shorthand for violence, misogyny, and homophobia, and of the importance of continually reflecting and challenging what is understood by the term. We were having a conversation that in many ways has mirrored shifts in the social and cultural location of men and boys at a popular cultural level. For example, studies of men and masculinities have tended to be obsessed with men. Of course, this 
seems to make sense: after all, is this not what the field is about? Yes and no. The obsession with exploring men and masculinity has led to an analytical framework that does not need to go beyond investigating what men do. We need to cultivate theoretical, conceptual, and methodological approaches that challenge existing frameworks.

One of the ways that this journal can make a difference to the critical study of men, sexualities, and masculinities is by providing space for scholars to develop emerging areas of study. The use of the special edition by the journal intends to do just that. We will see in a forthcoming volume of the journal an issue devoted to the study of the body and nakedness. How we understand and view nakedness is connected to the epistemological frames being employed, and we felt that a special issue in this area would help to highlight those frames more explicitly. We are also delighted to welcome a special edition led by our review editor, Andrea Waling, whose brilliant work on gender and sexualities will lead an exploration of the interplay between the dick pic and its role in configuring how we see bodies, sexualities, and masculinities. In the future, we are also planning to develop a special edition on researching masculinities and sexualities and how research practice is navigated personally, professionally, and in the field.

In so many ways, this journal has been percolating for years, and this is just the first step toward a first issue. Without question, journals take a lot of work and thought. And without question, journals make mistakes, take wrong turns, and need to make corrections. In each of these, the Journal of Bodies, Sexualities, and Masculinities is on the precipice, and we, as editors, are excited to learn, grow, and be a part of this wonderful burgeoning community. At the beginning of each semester, Frank tells his students that all the best learning requires reflexivity, developing an awareness of how to always grow, improve, and innovate. With the support of the prestigious Editorial Board and every author that has trusted us with their work, we believe that this journal can help grow the field of masculinity studies, crafting new research, theories, and methods, and fostering a robust community of writers, thinkers, scholars, researchers, photographers, poets, and artists.

Finally, it should be evident that we are developing a journal that aims to provide an inclusive and safe space, where novel ideas and innovative methodologies are most welcome. If any of the above discussion resonates with you or piques your interest, submit your articles or get in touch with the editors to discuss them. We are as excited to receive articles as hopefully you are in writing them and, as critical friends, the editorial team will read those articles sensitively and with care but also with a view to enabling them 
to be published in order to shape the future study of bodies, sexualities, and masculinities. In closing, we thank all those who have already been a part of this journey-from authors to reviewers, and most especially Berghahn Books, and we also thank those of you who will be joining us shortly.

Jonathan, Chris, and Frank

\section{References}

Davies, B. 1993. Shards of glass: Children reading and writing beyond gendered identities. New Jersey, USA: Hampton Press.

Halson, Jacqui. 1989. "The Sexual Harassment of Young Women." In Girls and Sexuality, ed. Lesley Holly, 130-143. Milton Keynes, UK: Open University Press.

Innes, Robert Alexander, and Kim Anderson, eds. 2015. Indigenous Men and Masculinities: Legacies, Identities, Regeneration. Winnipeg: University of Manitoba Press.

Leek, Cliff, and Markus Gerke. 2017. "Invisible and Unexamined: The State of Whiteness in Men's Studies Journals." International Journal of Gender Studies 6 (11): 29-44. doi:10.15167/2279-5057/AG2017.6.11.394.

Levisen, Carsten. 2017. "From Basic to Cultural Semantics: Postcolonial Futures for a Cognitive Creolistics." In Creole Studies-Phylogenetic Approaches, ed. Peter Bakker, Finn Borchsenius, Carsten Levisen, and Eeva Sippola, 381-385. Amsterdam: John Benjamin Publishing.

McKegney, Sam. 2014. Masculindians: Conversations about Indigenous Manhood. Winnipeg: University of Manitoba Press.

Tengan, Ty P. Kāwika. 2008. Native Men Remade: Gender and Nation in Contemporary Hawai $i$. Durham, NC: Duke University Press.

Tiidenberg, Katrin. 2020. "Research Ethics, Vulnerability, and Trust on the Internet." In Second International Handbook of Internet Research, ed. Jeremy Hunsinger, Matthew Allen, and Lisbeth Klastrup, 569-583. Dordrecht, Netherlands: Springer.

Tuana, Nancy. 2004. "Coming to Understand: Orgasm and the Epistemology of Ignorance." Hypatia: A Journal of Feminist Philosophy 19 (1): 194-232. https:// www.jstor.org/stable/3810938.

Van Bogaert, Knapp D., and Gboyega A. Ogunbanjo. 2009. "Feminism and the Ethics of Care." South African Family Practice 51 (2): 116-118. doi:10.1080/ 20786204.2009.10873822. 
Walsh, Peter William, and David Lehmann. 2019. "Academic Celebrity." International Journal of Politics, Culture, and Society. doi:10.1007/s10767-01909340-9.

Weeks, Jeffrey. 2007. The World We Have Won: The Remaking of Erotic and Intimate Life. Routledge: London.

Yar, Majid. 2012. "Recognition as the Grounds of a General Theory of Crime as Social Harm?" In Recognition Theory as Social Research, ed. Shane O'Neill and Nicholas H. Smith, 109-126. London: Palgrave Macmillan. 